\title{
Aumento das coxas com implantes de silicone
}

\author{
Thigh augmentation with silicone implants
}

Nicola Menichelli Netto ${ }^{1}$

Trabalho realizado nos Hospitais Albert Einstein, São Luiz e Saint Paul, São Paulo, SP, Brasil.

Artigo submetido no SGP (Sistema de Gestão de Publicações) da

RBCP.

Artigo recebido: $18 / 2 / 2011$ Artigo aceito: $30 / 4 / 2011$

\begin{abstract}
RESUMO
Introdução: $O$ implante de silicone para correção do volume dos membros inferiores teve início em 1979, com contínuo aumento de solicitação de pacientes em busca da melhoria estética do volume das pernas. Temos utilizado sua aplicação também nas coxas desde 1986, inicialmente em pacientes com sequelas de poliomielite e, a partir de 1995, em pacientes hígidos, interessados na melhoria da forma e do volume das coxas. Método: Sessenta e oito pacientes de ambos os sexos foram submetidos a implante de silicone nas coxas a partir de 1986 até a presente data. Foram sistematizados procedimentos técnicos para implantes posicionados isoladamente nas regiões ântero-interna e lateral, ou mesmo em conjunto numa mesma paciente no sentido de se obter melhor contorno e volume destas regiões. Detalhes técnicos estão descritos nas suas minúcias para cada tipo de procedimento. Resultados: $\mathrm{Na}$ sua maioria, estes pacientes têm sido acompanhados até a presente data, neste período de 15 anos, em que a reduzida incidência de cápsula clinicamente visível ou palpável, retirada de próteses e a ausência de extrusão têm compensado a sua indicação. Conclusão: Dada a baixa incidência de problemas secundários e a elevada qualidade estética a médio e longo prazo, tem havido contínuo aumento de pacientes que solicitam estes procedimentos.
\end{abstract}

Descritores: Coxas. Pernas. Próteses e Implantes. Implante de Prótese. Géis de Elastômeros de Silicone.

\begin{abstract}
Introduction: The use of silicone implants for the correction of the thin legs started on 1979 with continuous augment requested by the patients to improve the volume and shape. We have been applying these procedures in thighs since 1986, initially in the patients with polymielytis secuelae, and from 1995 on, in healthy people interested in shape and volume of the thigh aesthetic improvement. Methods: Sixty eight patients of both genders were submitted to thigh silicone implants from 1986 until today. Randomized technical procedures with isolated silicone implants at the internal and lateral aspects of the thigh root, even in combined procedures in the same or different surgical stages became a routine in an attempt to improve the volume and the thigh contour. Technical steps are described in details. Results: During these 15 years the majority of the patients have been followed. The minimal incidence of mild results, capsule contraction, if any, and removal or extruded implants have motivated to continue its indication and performance. Conclusion: Based in the low incidence of secondary problems and the high aesthetic results quality along medium and long term follow-up, continuous requests of these surgeries has been observed.
\end{abstract}

Keywords: Thigh. Leg. Prostheses and Implants. Prosthesis Implantation. Silicone Elastomers.

1. Membro titular da Sociedade Brasileira de Cirurgia Plástica; cirurgião plástico. 


\section{INTRODUÇÃO}

O comprometimento estético pela hipotrofia e formato das coxas em pacientes hígidos sempre marcou negativamente os seus portadores, particularmente nas mulheres. Os anseios e solicitações também sempre existiram até o aparecimento de tecnologia apropriada.

Os implantes de panturrilha tiveram suas primeiras publicações em 1979 com Carlsen ${ }^{1}$ e Glicenstein ${ }^{2}$, aplicados para casos de aumento de volume em pacientes pós-trauma, aos com sequelas de poliomielite e, a seguir, nos hígidos.

Em 1986, passamos a utilizar estes implantes nas coxas também para os com algum tipo de sequela que acarretasse atrofias e dismorfias volumétricas. Em 1995, esta rotina foi ampliada para pacientes hígidos com problemas estéticos de contorno e volume $\mathrm{e}^{3-9}$. As solicitações para estas cirurgias têm aumentado continuamente em função do custo e benefício e da reação em cadeia pela divulgação entre os próprios pacientes felizes com a melhoria estética obtida.

\section{Características estéticas}

A harmonia das coxas, pernas e pés determina parâmetros estéticos sempre avaliados como um todo ${ }^{10}$. Quando os maléolos internos e os joelhos se tocam, o mesmo ocorre ao longo da face interna das coxas que apenas se juntam sem sobras que se sobrepõem e nem deixam um espaço entre elas. $\mathrm{O}$ inverso determina espaços em função do geno valgo, atrofias musculares e adiposas. Estas desarmonias pela forma, volume e dimensões também são rapidamente analisadas dentro do aceitável ao inaceitável, em função da extensão de cada segmento dos membros inferiores. Os estudos neste artigo estão circunscritos às características das coxas, não entrando em detalhes mais abrangentes que envolvem as pernas também.

$\mathrm{O}$ contorno e o volume das coxas femininas e mesmo masculinas têm características estéticas integradas na cultura humana ao longo dos séculos. Distorções de forma e volume têm limites, os quais quando ultrapassados podem trazer aos seus portadores problemas emocionais cujas extensões nem sempre estão de acordo com o grau de dismorfias.

Dentre as queixas antiestéticas mais frequentes está a do aspecto arqueado na face medial da coxa, que deixa um espaço de variada amplitude em função da delgaces do panículo adiposo e do posicionamento e formato dos músculos adutores, gracilis e sartório, aliado a um espessamento das extensões aponeuróticas na região do canal de Hunter.

No sentido contrário ao das adiposidades laterais das coxas coloquialmente conhecidas por "culote de montaria", a falta de projeção lateral também causa efeitos pouco estéticos, com consequentes angústias.

Finalmente, problemas mais complexos de contorno têm requerido implantes na face lateral, anterior e posterior das coxas. Com muita frequência os problemas estéticos analisados nas coxas estão estendidos também para as pernas.
$\mathrm{O}$ presente artigo enfoca unicamente o tratamento das coxas. As Figuras 1 a 3 ilustram os tipos de pacientes que buscam estes tratamentos.

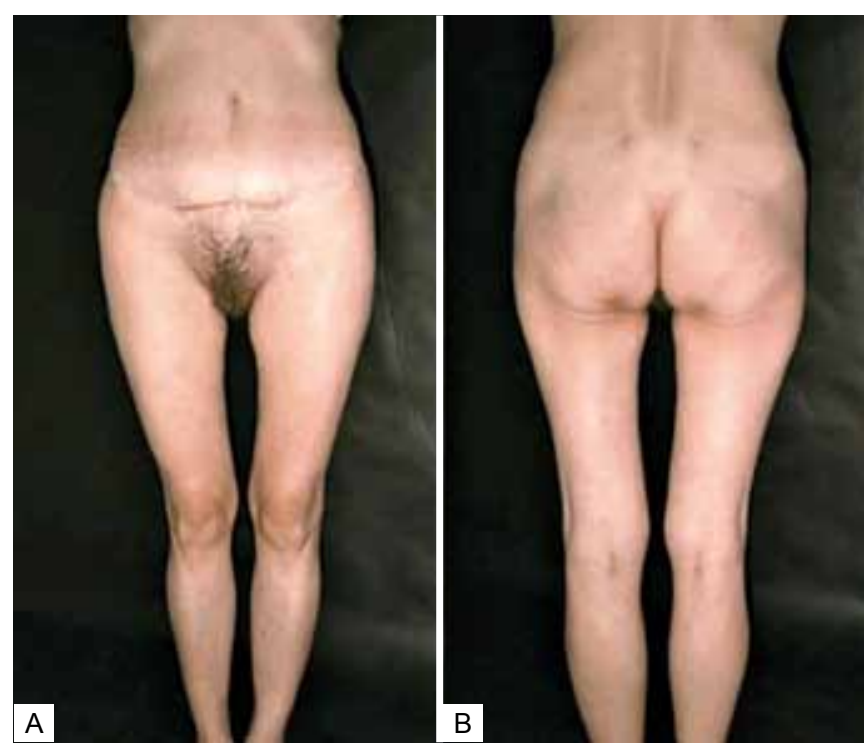

Figura 1-A e B: Vistas anterior e posterior de paciente do sexo feminino, com 48 de idade, que apresenta os membros inferiores de volume restrito decorrente dos músculos sem volume natural e mínima capa cutânea adiposa em todo o contorno do segmento médio superior das coxas, com nítida separação, causando efeito de magreza. São candidatas a implantes nas regiões interna, lateral, no mesmo tempo operatório.
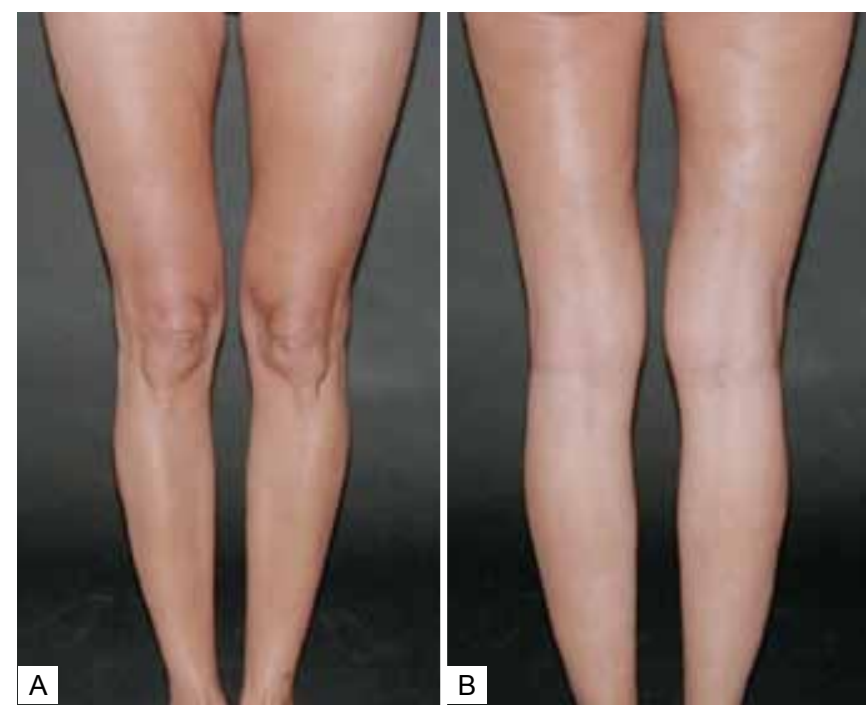

Figura 2-A e B: Vistas anterior e posterior de paciente do sexo feminino, com 58 anos de idade, demonstram o amplo espaço separando as faces internas e o limitado volume das coxas. $O$ contorno externo é normal, tornando-a candidata a implantes ântero-internos nas coxas. 


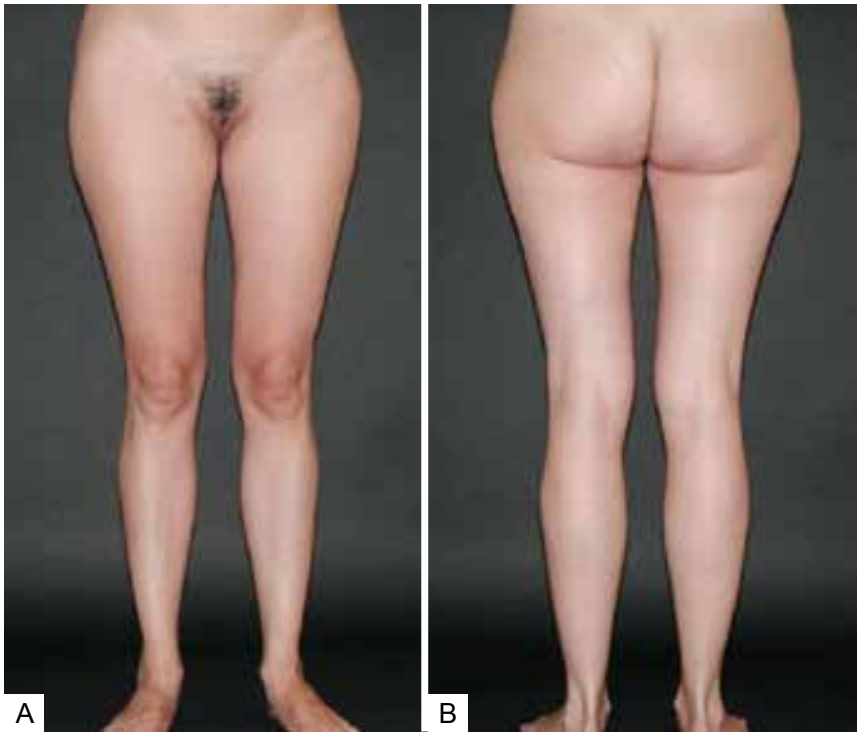

Figura 3-A e B: Vistas anterior e posterior de paciente do sexo feminino, com 29 anos de idade, demonstram projeção trocantérica normal e falta de projeção da face externa das coxas. Internamente o espaço interfemoral é amplo, sendo indicados implantes nas faces externas e ântero-interna das coxas.

\section{MÉTODO}

Foram operados 68 pacientes num total de 138 implantes, nos últimos 15 anos (1995 - 2010). Destes, 60 mulheres e oito homens, com idade mínima de 18 e máxima de 72 anos. A Figura 4 especifica o número e a faixa etária dos pacientes e a Figura 5, o volume das próteses.

Sessenta e quatro $(94 \%)$ pacientes receberam 123 próteses na face ântero-medial da coxa. Em três destes pacientes, ainda foi implantada uma prótese na face externa da coxa e somente $4(6 \%)$ receberam implantes exclusivamente na face lateral das coxas.

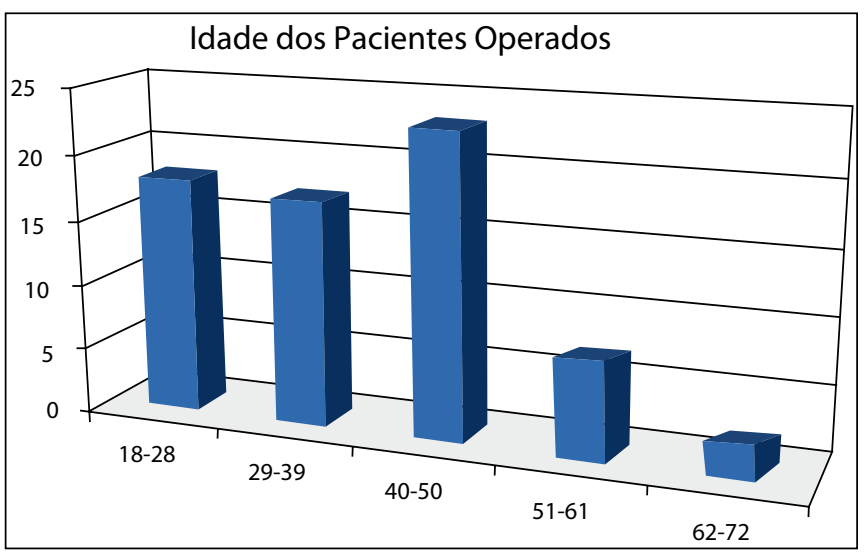

Figura 4 - Número e faixa etária dos pacientes operados.

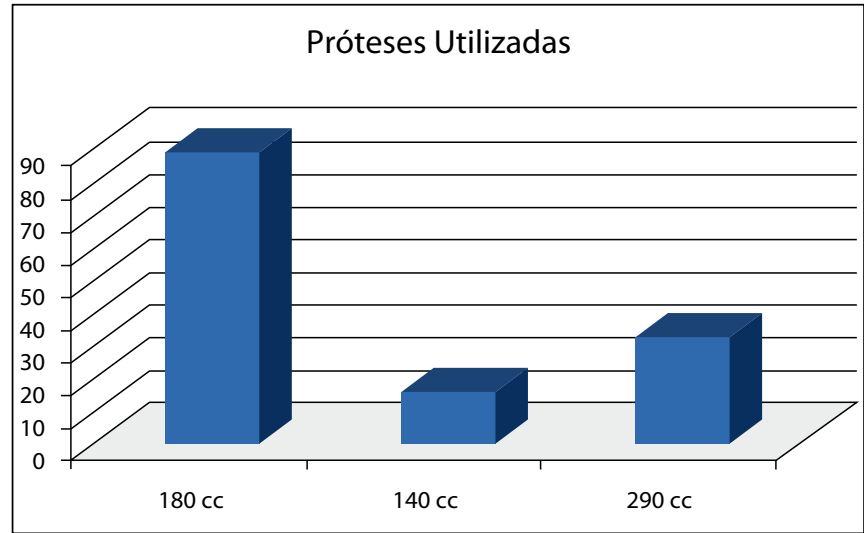

Figura 5 - Quantidade e volume dos implantes utilizados.

Tipos de próteses e de afastadores

Os implantes utilizados são de elastômeros de silicone. Diferentes, portanto, dos empregados para as mamas, que são gelatinosos. A consistência é branda, apesar do material ser sólido. Esse detalhe tem permitido sua introdução sem o uso de guias. A forma básica é elíptica, com ambas as extremidades arredondadas. As dimensões variam de acordo com o volume necessário para o preenchimento em cada caso. O comprimento varia de 23 a $29 \mathrm{~cm}$, e a largura máxima, de 4 a $6 \mathrm{~cm}$.

A Figura 5 especifica, em 68 pacientes operados, os volumes das 138 próteses utilizadas: 89 próteses de $180 \mathrm{ml}$, 16 de $140 \mathrm{ml}$ e 33 de $290 \mathrm{ml}$. A Figura 6 ilustra as configurações das próteses. A divulsão dos planos tissulares é realizada com afastadores maleáveis longos com 30,40 e $50 \mathrm{~cm}$ de comprimento por $3,5 \mathrm{~cm}$ de largura (Figura 7).

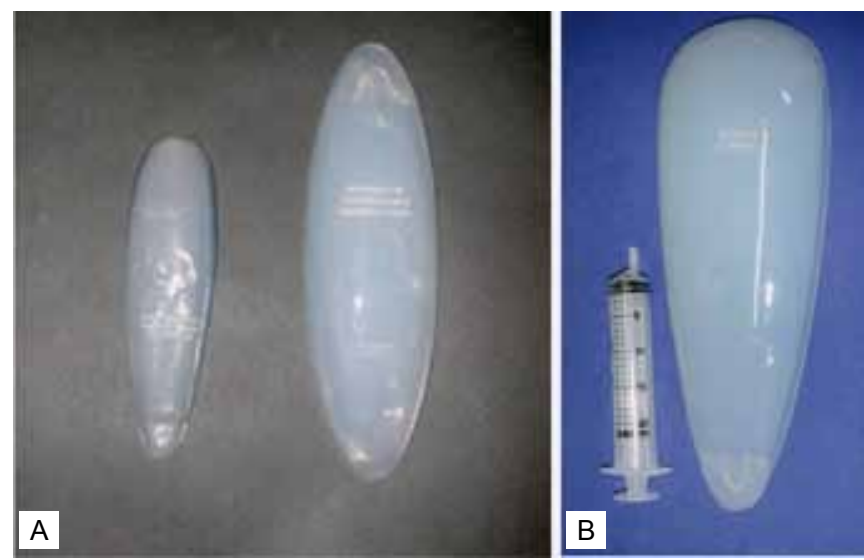

Figura 6-A: Tipos de próteses de silicone com o aspecto de uma elipse tridimensional de extremidades simétricas, com dois tipos volumes 180 a $290 \mathrm{~m}$ e dimensões de $23 \times 5,8 \times 2,6 \mathrm{~cm}$ e $29 \times 6,5 \times$ $2,5 \mathrm{~cm}$, respectivamente. B: As próteses de $320 \mathrm{ml}$ são assimétricas nas extremidades, de maneira a lembrar um hemifuso também tridimensional, de uso selecionado para a região superior e interna da coxa, permitindo melhor volume e contorno natural na região. 


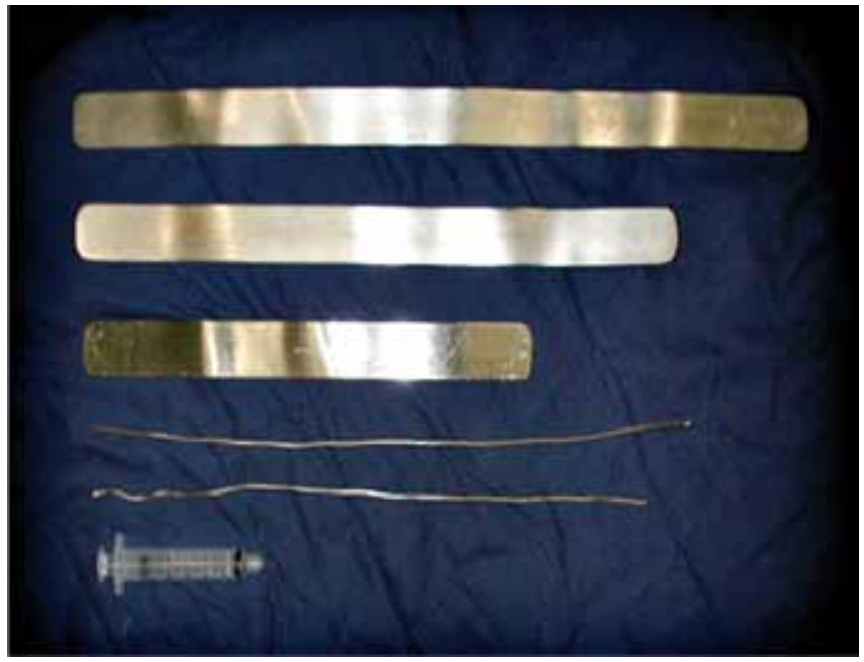

Figura 7 - Tipos de afastadores laminados e maleáveis com 30, 40 e $50 \mathrm{~cm}$ de comprimento por $3,5 \mathrm{~cm}$ de largura, usualmente aplicados para divulsionar os músculos da respectiva aponeurose, assim com criar espaços reais entre os planos músculoaponeuróticos.

\section{Anatomia cirúrgica}

São estudadas nos seus detalhes as duas regiões anatômicas ligadas aos implantes ${ }^{11-12}$ :

- $1^{\text {a }}$ Região ântero-interna - A concavidade natural na face medial da coxa se deve à configuração dos músculos sartório e adutor mediano, que se cruzam no terço médio, criando uma constrição abaixo do plano adiposo. $\mathrm{O}$ compartimento formado por estes músculos abriga, em sua parte profunda, os vasos femorais e o nervo safeno interno (conduto de Hunter). A prótese de silicone, que é implantada ao longo e entre estes dois músculos passa, nessa altura, por baixo do músculo sartório. Este é, sem dúvida, o ponto crítico da dissecção, que exige manobra atraumática, a fim de evitar lesões no nervo safeno acessório, que acompanha a face profunda do músculo sartório. Em resumo, a criação do estojo para a inclusão da prótese segue as manobras cirúrgicas: após a incisão cutânea, coincidente com a prega inguinal, inicia-se a dissecção subfascial no sentido caudal ao longo da borda lateral do músculo adutor mediano até o seu encontro com o músculo sartório, onde a progressão da dissecção com a lâmina maleável deve ser delicada para traumatizar o mínimo possível as estruturas vizinhas e suficiente para a elaboração do espaço que conterá a prótese (Figura 8).

- $2^{\mathrm{a}}$ Região Lateral da Coxa - O procedimento envolve a região do músculo tensor e a respectiva fáscia lata. $\mathrm{O}$ ato cirúrgico é o de criar um espaço entre a fáscia lata $\mathrm{e}$ o músculo vasto lateral, subjacente a ela, que conterá o implante (Figura 9).

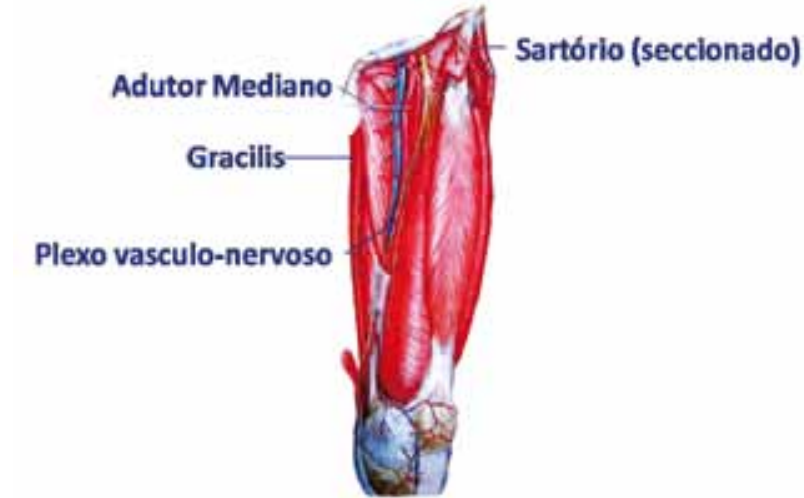

A

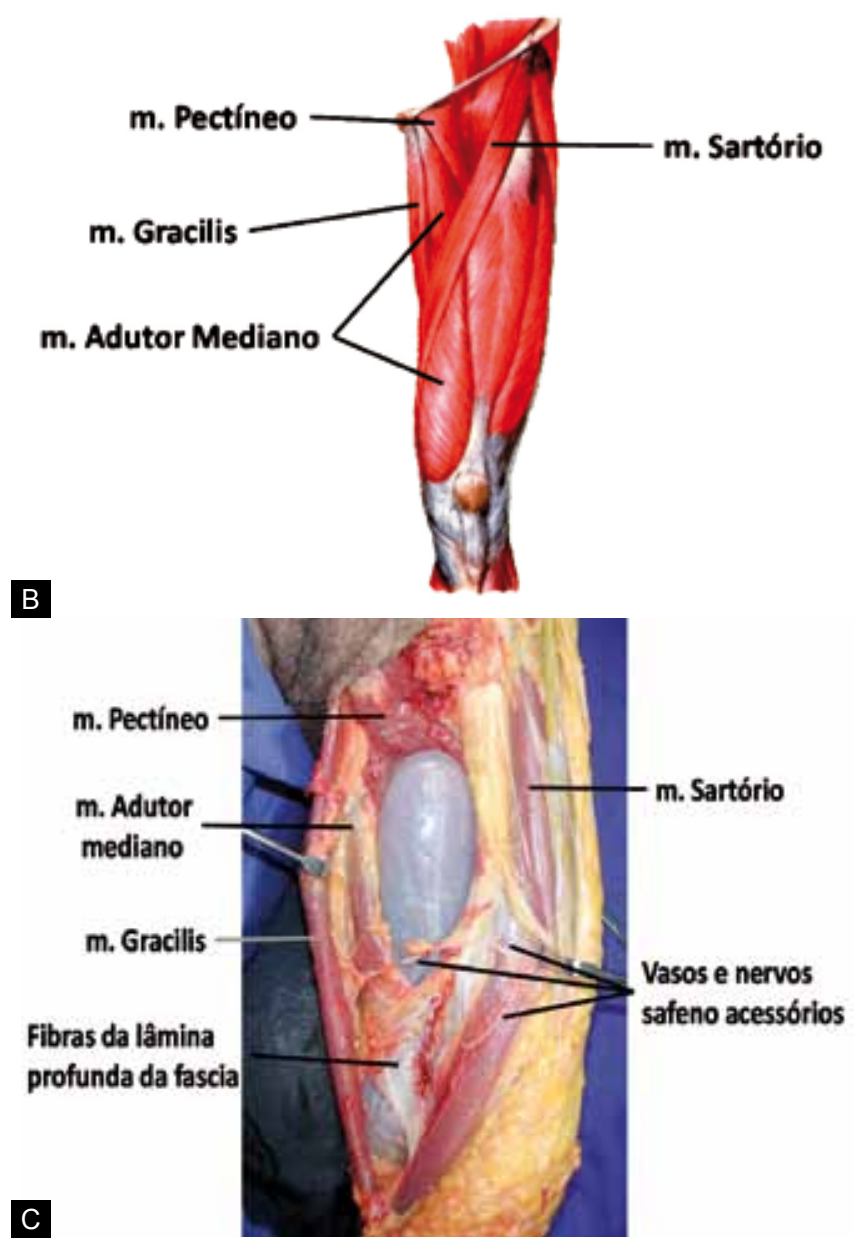

Figura 8-A: Aspectos esquemáticos do conduto de Hunter e do triângulo de Scarpa que demonstram o músculo sartório rebatido, a base do leito receptor da prótese sobre os dois músculos adutor mediano e o pectíneo, medialmente ao músculo gracilis e lateralmente ao plexo vásculo-nervoso da coxa. B: Triângulo de Scarpa, formado pelo arco crural, músculo sartório e músculo gracilis. $\boldsymbol{C}$ : Dissecção em cadáver ilustra nos detalhes a posição da prótese e do sistema músculo aponeurótico. 


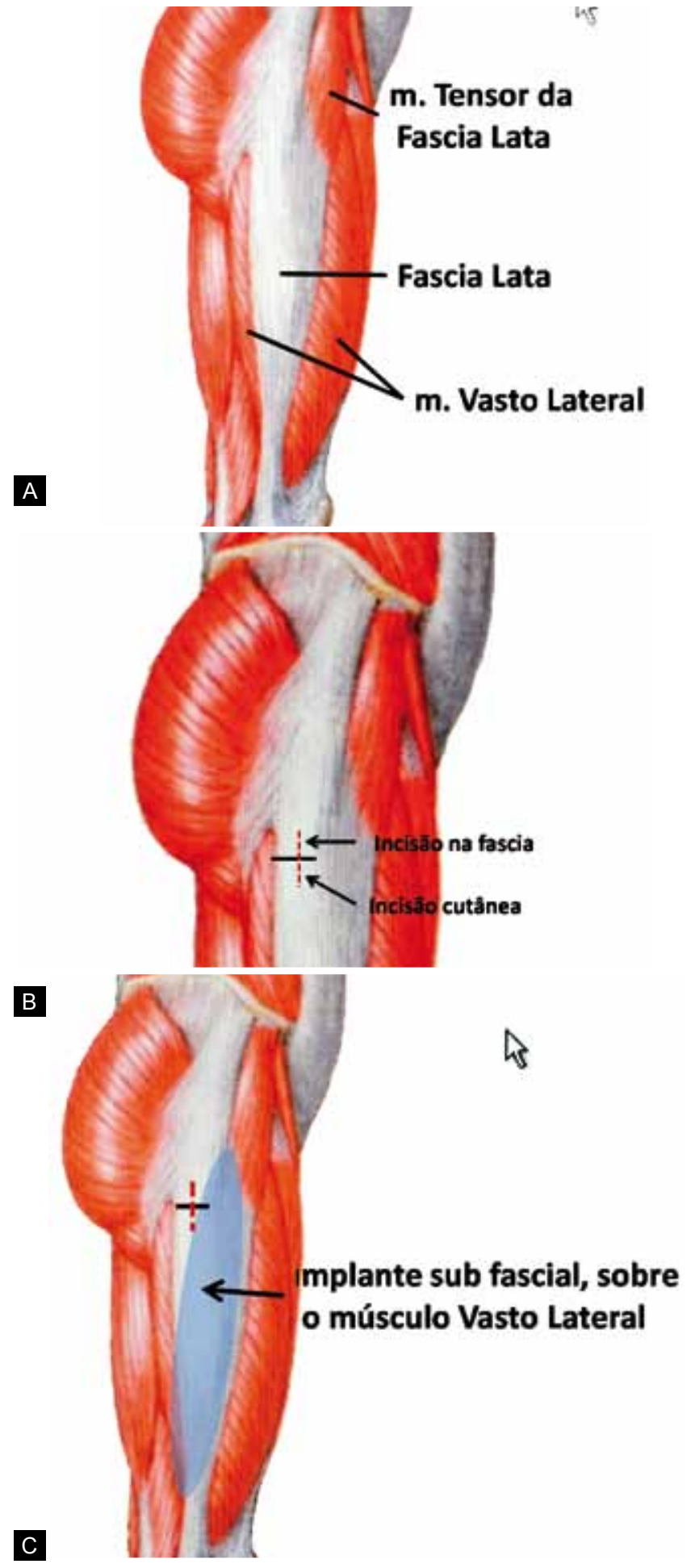

Figura 9 - A: Músculos e aponeuroses da região lateral da coxa. B: Incisão cutânea transfixante eclética e cruzada na pele e na fascia para evitar superposição de suturas. C: Aspectos esquemáticos da dissecação e localização da prótese na coxa. A projeção cutânea da prótese mostra o seu posicionamento ao longo da região lateral da coxa.

\section{Técnica cirúrgica}

Dois tipos de cirurgias têm sido realizados de maneira isolada ou combinada, no mesmo ou em tempos operatórios diferentes, num mesmo paciente:

1. Os implantes na região ântero-medial são introduzidos com o paciente em decúbito dorsal horizontal, sob anestesia geral ou epidural. Em nenhuma circunstância fazemos infiltração local com ou sem epinefrina. A via de acesso cutânea de 4 a $5 \mathrm{~cm}$ é no sulco inguinal, sobre a projeção cutânea do músculo adutor mediano, cujo tendãoé palpável neste nível, até atingir e incisar a fáscia femoral e expor os ventres e tendões dos músculos adutores e pectíneo. A dissecação inicialmente é digital ao longo da face anterior da coxa, lateralmente ao tendão do adutor mediano até o limite de alcance do dedo. A seguir, a dissecação é feita com espátula de lâmina maleável, paralela e medial ao músculo sartório, até atingir o nível determinado na avaliação préoperatória. A implantação da prótese é manual e não exige guia. A sutura da fáscia é realizada com pontos isolados de fio absorvível 3-0 e, na pele, também com pontos isolados de material absorvível 4-0, com o nó internamente posicionado. A sutura é protegida com fita adesiva porosa e a paciente é levada da sala cirúrgica vestida com uma meiacalça elástica (Figuras 10 a 12);
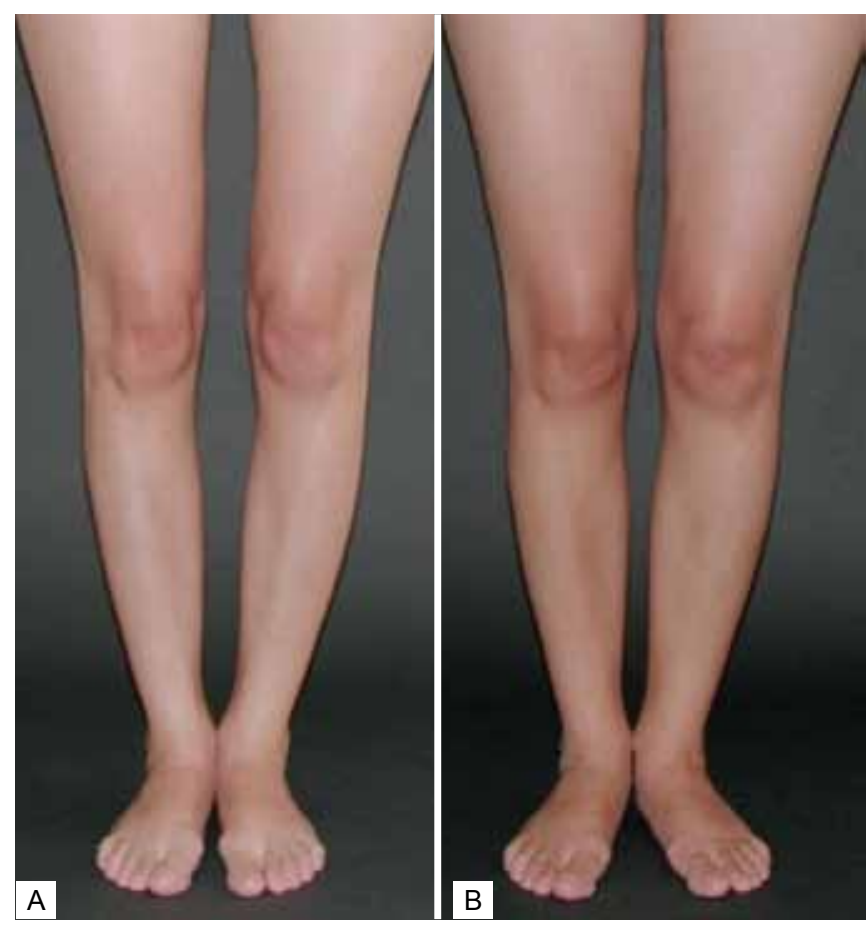

Figura 10-A e B: Vista anterior do pré e seis meses de pósoperatório numa paciente de 29 anos de idade, com reduzido volume adiposo e muscular na face interna das coxas, enquanto o contorno externo apresenta-se natural. Implantes de $320 \mathrm{cc}$ bilateral na face interna das coxas, com nitida melhoria estética. 


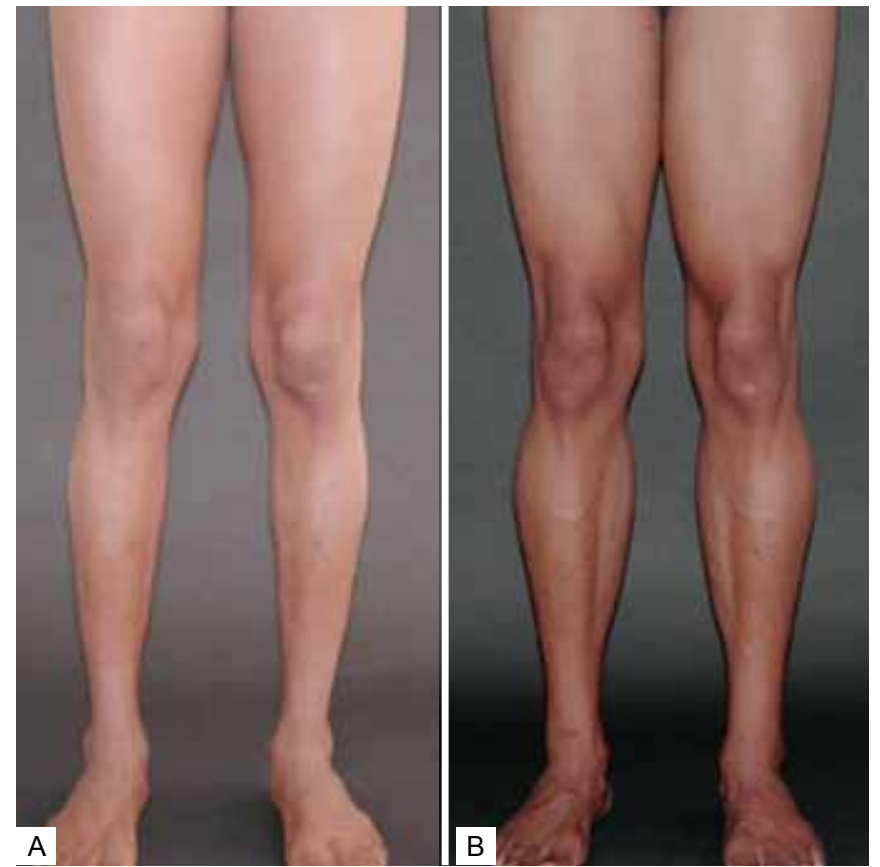

Figura 11 - A e B: Vista anterior do pré-operatório e 3 anos após o procedimento de paciente do sexo masculino, com 22 anos de idade, com queixa de hipotrofia medial das coxas. Foram implantadas próteses de 290 cc, em ambas as coxas.

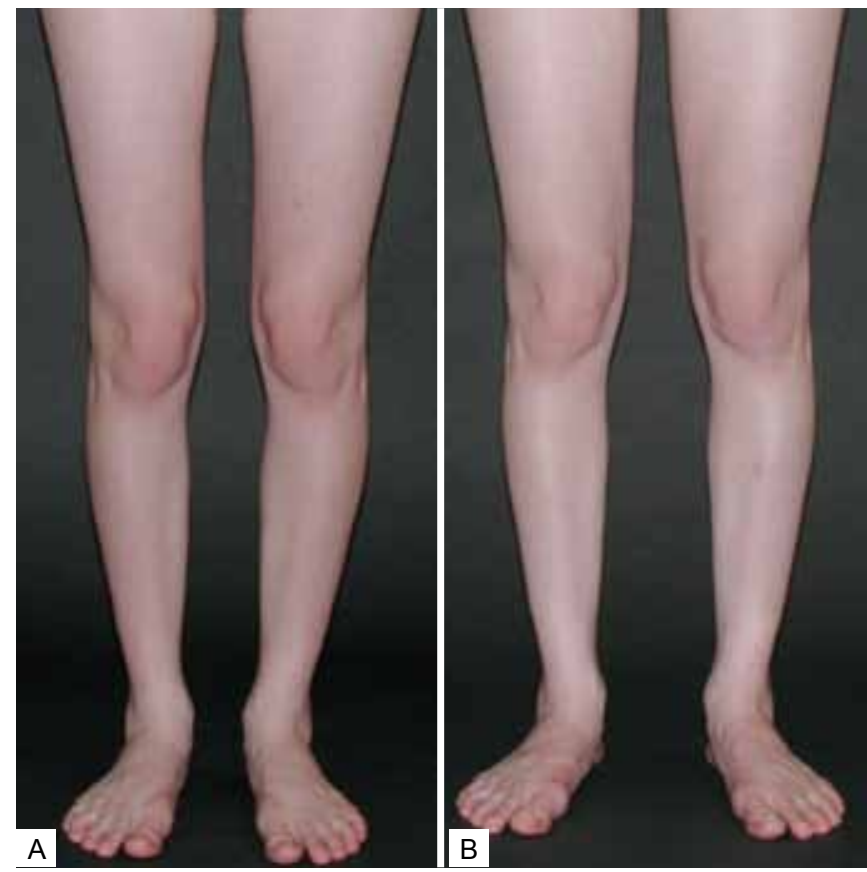

Figura 12 - Paciente do sexo feminino, de 22 anos de idade, com queixa de hipotrofia nas faces mediais das coxas. A: Aspecto préoperatório; B: Oito meses após a colocação de implantes de $180 \mathrm{cc}$ nas faces mediais das coxas.
2. Nos implantes laterais da coxa, os pacientes são operados em decúbito lateral, com a coxa e a perna levemente flexionadas. A via de acesso cutânea é realizada através de incisão superior transversal de $4 \mathrm{~cm}$, na altura do sulco glúteo. A seguir, a fáscia é incisada no sentido contrário ao da pele e a divulsão com afastador de 3,5 cm de largura é efetuada ao longo da coxa, entre a fáscia lata e o músculo vasto lateral, que constitui o plano mais profundo. Não há resistência a esta dissecação por haver um plano natural de clivagem, porém o espaço é sempre justo. Pode-se introduzir implantes de 23 ou $29 \mathrm{~cm}$ de comprimento, que equivalem 180 e $290 \mathrm{cc}$, respectivamente. Uma segunda via de acesso opcional pode ser utilizada. É posicionada no extremo distal da coxa, a incisão cutânea transversal tem a extensão de $3,5 \mathrm{~cm}$ de comprimento e situa-se aproximadamente $5 \mathrm{~cm}$ acima do côndilo lateral do fêmur. $\mathrm{O}$ plano de clivagem é o mesmo e o sentido da divulsão é inverso. A sutura da fáscia se processa com pontos isolados de material absorvível 3-0 e, da pele, com pontos de material absorvível 4-0, nos mesmos padrões descritos anteriormente (Figuras 12 a 15).
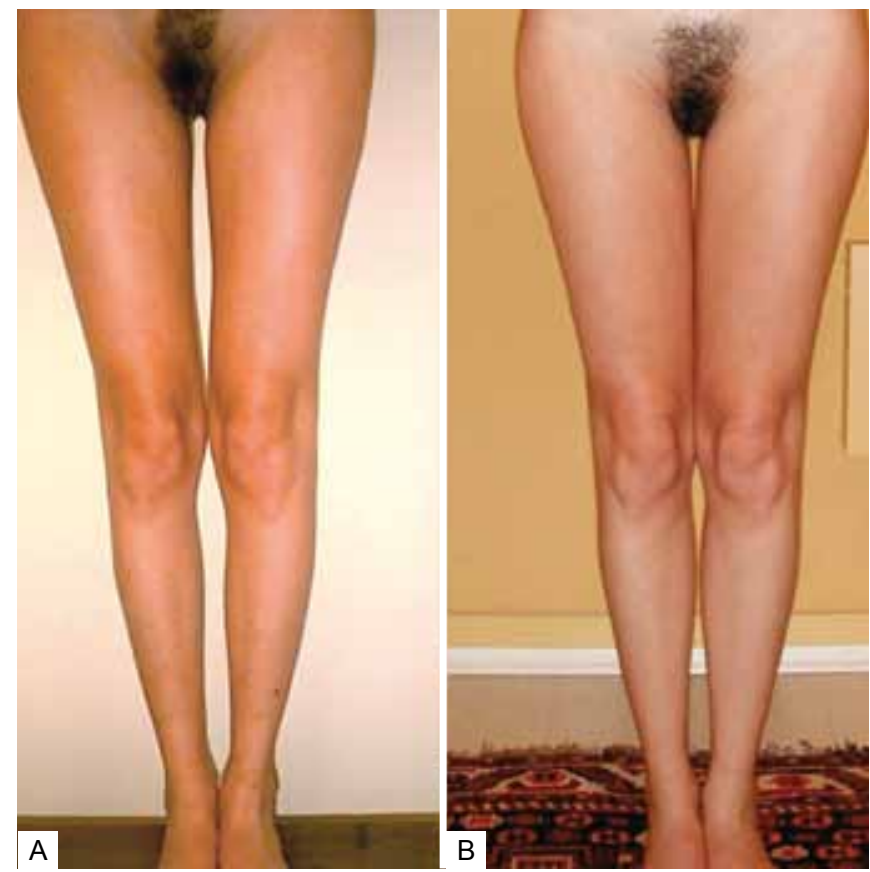

Figura 13 - A e B: Vista anterior do pré-operatório e 2 anos após o procedimento de paciente de 27 anos de idade, com as faces mediais e laterais das coxas afiladas. Foram implantadas próteses de $180 \mathrm{ml}$ nas faces internas, obtendo-se contornos mais volumosos e esteticamente melhor contorneados. 


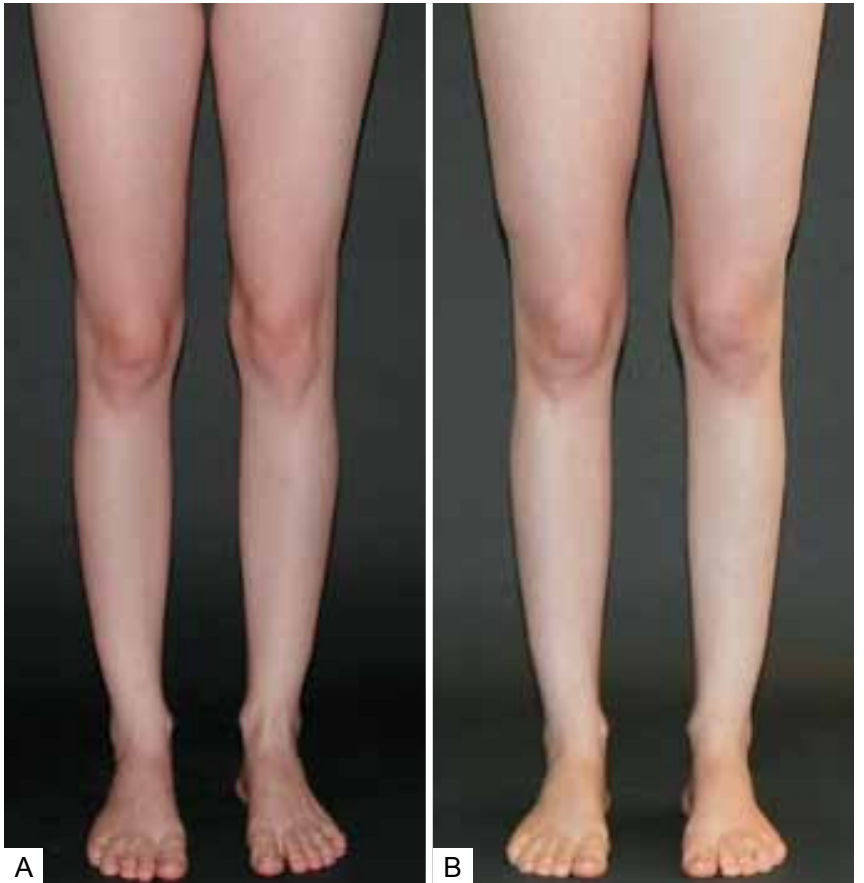

Figura 14 - Paciente do sexo feminino, de 23 anos de idade, apresentando acentuada delgaces em toda a coxa. A: aspecto pré-operatório; B: pós-operatório de 6 meses da colocação de implantes de $180 \mathrm{cc}$ nas faces mediais e laterais das coxas. $O$ implante lateral, assimétrico, foi colocado de forma invertida para simular a musculatura vasto-lateral.
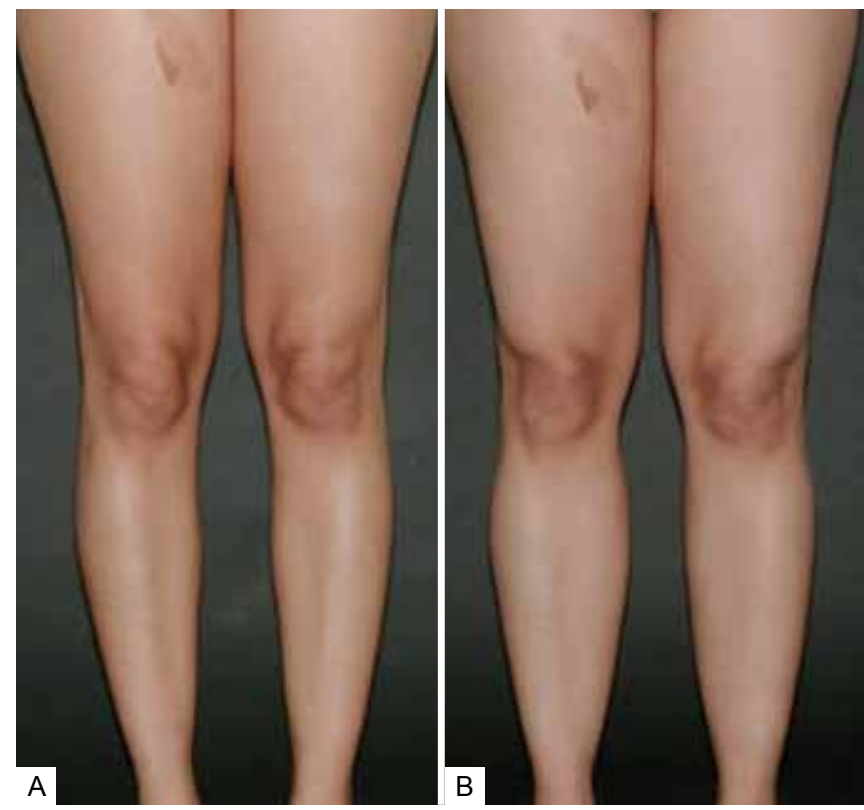

Figura 15 - Paciente do sexo feminino, de 26 anos de idade, policial militar, desejava um aspecto mais musculoso da coxa. A: aspecto pré-operatório; $\boldsymbol{B}$ : dois anos após a colocação de implantes nas faces laterais das coxas.

\section{Cuidados pós-operatórios}

A paciente é vestida ainda na sala de cirurgia com uma meia-calça elástica de suave compressão, desde a extremidade dos dedos dos pés até o quadril, que permanece durante 7 a 10 dias iniciais do pós-operatório. A internação é de 12 a 24 horas, deambulando desde as primeiras horas após liberação pelo anestesista. Antibioticoterapia é instituída nos primeiros 4 dias de pós-operatório. $\mathrm{O}$ edema e equimoses são raros e a dor bastante suportável com o uso de analgésicos. A primeira revisão é realizada, em média, uma semana após o procedimento. Neste período, o paciente pode exercer atividades domésticas. Após 2 semanas, o paciente está autorizado a retornar às atividades habituais e ao trabalho e, após 45 dias, à prática de esportes.

\section{RESULTADOS}

$\mathrm{Na}$ casuística dos 68 pacientes operados, foram registrados um caso de hematoma, que evoluiu espontaneamente para a reabsorção e um seroma drenado por punção. Não foi observada nenhuma infecção e nem paraestesias permanentes. Em alguns pacientes, não registrados numericamente, ocorreram discretas assimetrias de forma e volume, dos quais dois tiveram indicação de reposicionamento das próteses, porém não foram corrigidos até a presente data pela não decisão dos pacientes.

Quatro pacientes tiveram que ser reoperados, sendo dois por dor excessiva no pós-operatório imediato, decorrente de traumatismo do ramo superficial do nervo safeno, o terceiro, pela má posição do implante na coxa esquerda. Nestes pacientes, os implantes foram reposicionados, evitando-se assim a remoção temporária dos mesmos. O quarto paciente teve forte dor por traumatismo do nervo safeno, com a retirada dos implantes e não mais reposicionado por recusa do mesmo. Duas outras remoções ocorreram por ruptura dos implantes após 10 anos. Coincidentemente ambos eram portadores de HIV.

Até a presente data, somamos 61 pacientes sem nenhum tipo de problema e alto grau de satisfação e 9 com as intercorrências descritas.

\section{DISCUSSÃO}

A indicação seletiva para os implantes múltiplos está, como registramos anteriormente, em oferecer aos pacientes um contorno mais harmonioso e volumoso na raiz das coxas. Conseguimos, durante este período de 15 anos, evoluir seletiva e continuamente, iniciando com implantes na região ânteromedial e, em seguida, para a externa num mesmo paciente.

Os implantes gelatinosos têm alta tendência a rompimento com o tempo, porém não necessariamente devem ser substituídos, porque a cápsula fibrosa ao redor da prótese 
pode conter o gel extravasado. Este fato parece não ter ocorrido nos dois pacientes portadores de HIV citados.

Há 10 anos, passamos a utilizar implantes sólidos constituídos de elastômeros de silicone, que não sofreram ruptura até a presente data. Paralelamente, observamos que as cápsulas fibrosas são muito finas, de maneira a transmitir a maciez natural da coxa à palpação.

As indicações e os procedimentos técnicos descritos e os resultados a curto, médio e longo prazo, apesar das intercorrências e complicações registradas, têm apresentado relação custo-benefício compensadora.

À medida que os resultados têm sido vistos pelo público com problemas desta natureza, a procura tem aumentado. Importante é registrar a qualificação do profissional em todas as etapas cirúrgicas, incluindo também a indicação específica para cada caso.

\section{CONCLUSÃO}

A cirurgia do contorno das coxas por falta de volume passou por duas fases, em que implantes subfaciais foram aplicados inicialmente na região ântero-medial, evoluindo depois para as regiões laterais, de maneira a determinar um aumento circunferencial harmônico aos pacientes.

O baixo risco cirúrgico e de efeitos secundários tem determinado aumento na procura destes procedimentos, pelo elevado benefício estético aos portadores de problemas de atrofias das coxas.

\section{REFERÊNCIAS}

1. Carlsen L. Calf augmentation: a preliminar report. Ann Plast Surg. 1979;2(6):508-10.

2. Glicenstein J. Correção das amiotrofias dos membros por inclusão de próteses de silicone. Rev Bras Cir. 1979;69:177.

3. Menichelli Netto N. Implantes de silicone em membros inferiores e nádegas. In: Sociedade de Medicina e Cirurgia de Campinas;1996;São Paulo, Brasil.

4. Menichelli Netto N. Correction of limb deformities with silicone prostheses. Aesthetic Plast Surg. 1999;23(2):134-8.

5. Menichelli Netto N. Inclusão simultânea de próteses de silicone em pernas, coxas e nádegas. In: $39^{\circ}$ Congresso da Sociedade Brasileira de Cirurgia Plástica;2002; Salvador, Brasil.

6. Menichelli Netto N. Inclusão de próteses de silicone em membros

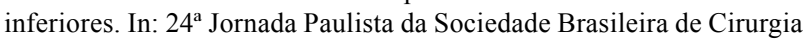
Plástica; 2004; São Paulo, Brasil.

7. Menichelli Netto N. Limb augmentation with silicone implants: full correction. In: Abstracts X ESPRAS (European Society of Plastic and Reconstructive Aesthetic Surgery) Congress; 2005; Viena, Áustria. p.138.

8. Menichelli Netto N. Inclusão de próteses de silicone em membros inferiores. In: Stochero I, Tournier AB, eds. Atualização em cirurgia plástica estética e reconstrutiva. São Paulo:Robe;2005. p.463.

9. Menichelli Netto N. Lower Limbs aesthetic surgery with silicone implants. In: Abstracts XI ESPRAS (European Society of Plastic and Reconstructive Aesthetic Surgery) Congress;2009; Rhodes, Greece. p.289.

10. Montellano L. Correção estética das deformidades da perna. In: Mélega JM, ed. Cirurgia Plástica Fundamentos e Arte - Cirurgia Estética. Rio de Janeiro: Medsi;2003. p.771-6.

11. Testut L, Jacob O. Tratado de anatomia topográfica. Tomo II. Rio de Janeiro:Salvat; 1952

12. Ferner H, Straubesant J. Sobotta Atlas de Anatomia. vol. II. Rio de Janeiro:Guanabara-Koogan;1982.

\section{Correspondência para:}

Nicola Menichelli Netto

Rua Bastos Pereira, 145 - Vila Nova Conceição - São Paulo, SP, Brasil - CEP: 04507-010

E-mail: nicola@nicolamenichelli.com.br 